\title{
SOSIALISASI PENANAMAN DENGAN METODE HYDROPONIK DI KECAMATAN SAGULUNG
}

\section{PLANTING SOCIALIZATION BY USING HYDROPONIC METHOD AT SAGULUNG DISTRICT}

\author{
Muhammad Solihin \\ Program Studi Ilmu Pemerintahan, Fakultas Ilmu Sosial dan Ilmu Politik, \\ Universitas Riau Kepulauan, Indonesia \\ sm10rome@gmail.com
}

\begin{abstract}
Abstrak
Dari permasalahan harga sayur-sayuran yang melambung tinggi di Kota Batam kami merencanakan kegiatan pengabdian kepada masyarakat yakni Sosialisasi Penanaman dengan metode Hydroponik yang (1) untuk mengalakkan program urban farming di kota Batam; dan (2) Untuk memberikan pengetahuan penanaman dengan metode hidroponik kepada masyarakat kelurahan Sei Pelungut, Kecamatan Sagulung, Kota Batam.. Penelitian ini mengunakan metode deskriptif kualitatif. Teknik pengumpulan data dengan cara observasi dan wawancara sehingga menghasilkan data primer. Teknik analisis dengan merkumpulkan data, reduksi data, penyajian data, dan penarikan kesimpulan dan verifikasi. Hasil penelitian yakni sosialisasi dilakuan dengan tahapan Pertama, Pengenalan media tanam hidroponik; Kedua, Pengenalan bibit dan sosialisasi cara pembibitan; Ketiga, Melakuan pemindahan bibit dan pengenalan waktu panen. Kesimpulannya, Masyarakat sangat antusias dalam membantu pelaksanaan kegiatan yang diadakan terutama para ibu-ibu kavling flamboyan yang selalu ikut dalam rangkaian kegiatan. Kegiatan ini memiliki potensi yang cukup besar untuk dikembangkan di tempat lainnya sehingga dapat membuat dampak yang lebih besar pada masa yang akan datang, terutama bagi masyarakat yang tidak mampu.
\end{abstract}

Kata Kunci: Perkebunan Kota, Masyarakat Miskin Kota, Hidroponik

\begin{abstract}
From the problem of vegetable prices that soar high in Batam City we are planning activities to the community devotion of Planting Socialization with Hydroponics method (1) to urban urban farming program in the city of Batam; and (2) To provide knowledge of planting with hydroponics method to community of Sei Pelungut Village, Sagulung Sub-district, Batam City. This research uses qualitative descriptive method. Technique of collecting data by observation and interview so as to produce primary data. Technique of analysis by collecting data, data reduction, data presentation, and conclusion and verification. The results of research that is socialization dilakuan with stages First, Introduction of hydroponic planting media; Second, the introduction of seedlings and the socialization of seedlings; Third, Melakukan transfer of seeds and the introduction of harvest time. In conclusion, the community is very enthusiastic in assisting the implementation of the activities, especially the mothers of the flamboyant lot who always participate in the series of activities. This activity has considerable potential to be developed elsewhere so that it can make a bigger impact in the future, especially for people who can not afford.
\end{abstract}

Keywords: Urban Farming, Urban Poor, Hydroponics 


\section{PENDAHULUAN}

Berangakat dari pentingnya penerapan Tri Dharma perguruan tinggi yang terdiri dari tiga unsur penting yaitu pendidikan, penelitian dan pengabdian pada masyarakat. Dengan ini Dosen di tuntut aktif dalam pengabdian kepada masyarakat khususnya dalam memecahkan masalah-masalah yang dialami oleh masyarakat sekitar. Masyarakat dan segala permasalahannya dengan cara kerja antar sektor atau interdisipliner. Melalui kegiatan pengabdian masyarakat, Dosen tidak sekedar pintar secara teoritik namun juga secara praktis dengan menginventarisir permasalahan, potensi dan sumber daya serta mampu memberikan alternatif pemecahan masalah dan analisis pengembangan potensi dan sumber daya yang ada pada masyarakat. Dengan kegiatan pengabdian pada masyarakat, mengamalkan ilmu, teknologi dan seni untuk memecahkan masalah tersebut dan menanggulangi secara pragmatis.

Kegiatan pengabdian masyarakat ini berlokasi di Kavling Flamboyan, Kelurahan Sei Pelungut, Kecamata Sagulung, Kota Batam. Sudah menjadi permasalahan umum di kota Batam bahwa harga kebutuhan dasar tergolong sangat tinggi sehingga membuat beban hidup di Kota ini sungguh sangat tinggi walaupun UMK sudah mendekati tertinggi yakni Rp 3.200.000,-/bulan. Permasalahan tingginya bahan pokok khususnya sayuran membuat warga kesulitan. Di Batam sayur-sayuran yang biasanya dikota-kota lain harganya terjangkau, di kota Batam sayuran di timbang. Tingginya harga bahan pokok di pasar basah Fanindo Batu Aji, bayam dijual Rp 18.000,-/kg yang sebelumnya hanya Rp 8.000,/kg. Kacang Panjang yang biasanya di jual Rp 14.000,-/kg saat ini dijual Rp 20.000,-/kg. Menurut hasi wawancara dari Ayun (32 Tahun), Seorang ibu rumah tangga mengaku terpaksa mengurangi pembelian.

"Kalau begini terus kami jadi pusing. Semua serba mahal. Karena kita butuh, mau tidak mau harus dibeli meskipun harus membeli lebih sedikit" $(1 / 08 / 2017)$

Kondisi ini juga diakui oleh pedagang di pasar basah Fanindo yang tentu serba salah karena ditataran pedagang memang membeli dengan modal yang cukup tinggi. Tentu tidak mungkin mereka menjual dibawah harga modal. Hasil Wawancara dengan Sindi (45 
Tahun) pedagang di pasar basah Fanindo, yang bercerita sayurnya sering busuk karena tidak laku atau sepih pembeli.

\begin{abstract}
"Memang kenaikan sayur paling tinggi khususnya untuk bayam, timun dan sayur lainnya yang mencapai 50 persen. Banyak sayur dagangan saya yang busuk karena tidak laku, kami Rugi." (1/08/2017)
\end{abstract}

Dari permasalahan harga sayur-sayuran yang melambung tinggi tersebut kami Tim Pengabdian Kepada Masyarakat Universitas Riau Kepulauan memikirkan solusi yang tepat guna memecahkan permasalahan masyarakat Kota Batam tersebut. Akhirnya kami merencanakan kegiatan pengabdian kepada masyarakat yakni Sosialisasi Penanaman dengan metode Hydroponik yang tentu masih asing bagi kalangan masyarakat. Pada tahap awal kegiatan dilakukan dengan objek yakni Ibu-Ibu Warga RW 014 Kel.Sei Pelenggut, dimana Hydroponik ialah metode penanaman tanpa media tanah sama sekali, namun menggunakan media air yang dikandung nutrisi cukup bagi tanaman Hydroponik, Hydroponik secara umum dapat menggunakan media tempat Pipa Paralon dan Aqua Botol bekas.

Berdasarkan latarbelakang tersebut penulis merumuskan masalah penelitian ini sebagai berikut: Bagaimana sosialisasi penamanan dengan metode hidroponik di kelurahan Sei Pelungut, Kota Batam. Adapun tujuan penelitian ini adalah (1) untuk mengalakkan program urban farming di kota Batam; dan (2) Untuk memberikan pengetahuan penanaman dengan metode hidroponik kepada masyarakat kelurahan Sei Pelungut, Kecamatan Sagulung, Kota Batam.

\title{
METODOLOGI
}

Penelitian ini mengunakan metode deskriptif kualitatif menurut Mulyana (2003: 150) metode penelitian kualitatif tidak perlu mengandalkan bukti bedasarkan logika matematis, prinsip angka, atau metode statistik. Creswel (2010) menjelaskan realitas social adalah rangkaian makna dalam menjalankan kehidupan ilmu didasarkan pada pengetahuan seharihari, bersifat induktif, dan tidak bebas nilai. Realitas social pada penelitian ini adalah sebuah kegiatan sosialisasi penanaman dengan metode hidroponik dengan daerah kegiatan di perkotaan kota Batam, atau bisa juga disebut kajian urban farming. Teknik pengumpulan data dengan cara observasi dan wawancara pada kegiatan sehingga menghasilkan data primer. 
Teknik analisis data penelitian ini adalah sebagai berikut (1) Merkumpulkan data, setelah itu dilakukan reduksi data; (2) Kemudian data disajikan dalam bentuk gambar dan penjelasan deskriftif; dan (3) Penarikan kesimpulan dan verifikasi.

\section{PEMBAHASAN}

Penanaman secara metode Hydroponik masih asing bagi kalangan Ibu-Ibu Warga RW 014 Kel.Sei Pelenggut, dimana Hydroponik ialah metode penanaman tanpa media tanah sama sekali, namun menggunakan media air yang dikandung nutrisi cukup bagi tanaman Hydroponik, Hydroponik secara umum dapat menggunakan media tempat Pipa Paralon dan Aqua Botol bekas. Hydroponik sendiri di terapkan dengan kelebihannya dapat menanam meskipun para warga tidak memiliki pekarangan rumah, penanaman hydroponic sebenarnya lebih cocok untuk tanaman jenis sayur-sayuran,dan penanaman apotik hidup seperti jahe,kunyit,Sirih merah, dan lain-lain. Pencapaian kegiatan ini ialah agar warga sekitar dapat menerapkan Hydroponik sebagai cara alternatif menanam tanpa membutuhkan lahan yang luas,dan menghemat waktu . Di mulai pukul 10.00 -16.00 WIB,Hari Sabtu Tanggal 19 Agustus 2017 dan 26 Agustus 2017.

1. Pengenalan Media Tanam Hydroponik

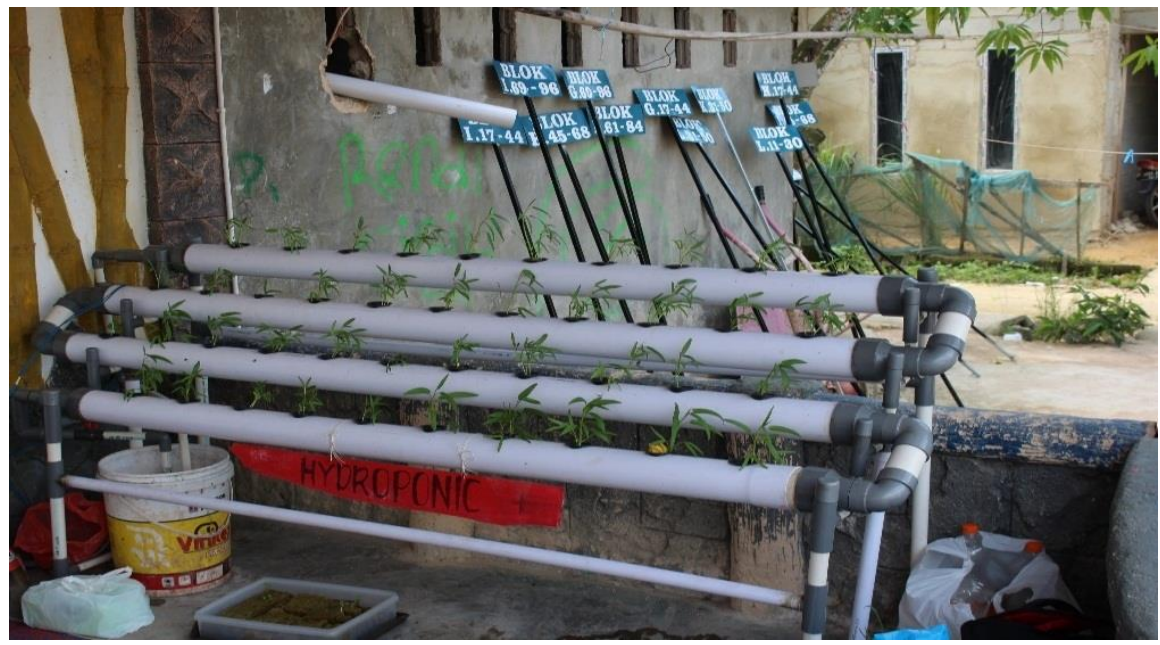

Gambar 1. Media Tanam dari Paralon

Pada tanggal 19 agustus masyakarat kavling Flamboyan RW 14 Sei Pelungut dikenalkan pada media tanam dengan cara Hydroponik. Masyarakat dikenalkan 
dengan bahan-bahan yakni paralon dan cup bekas aqua gelas sebagai potnya. Masyarakat juga diperagahkan bagaimana memasang dari awal pembuatan media tanam Hydroponik tersebut.

2. Pengenalan Bibit dan Sosialisasi Cara Pembibitan

Pada tanggal 19 agustus masyarakat dikenalkan tentang bibit dan cara bagaimana melakukan pembibitan. Ada banyak jenis bibit yang dikenalakan yakni, sawi, bayam, kankung dan jenis tumbuhan lainnya yang dapat hidup dengan cara tanam hydroponic.

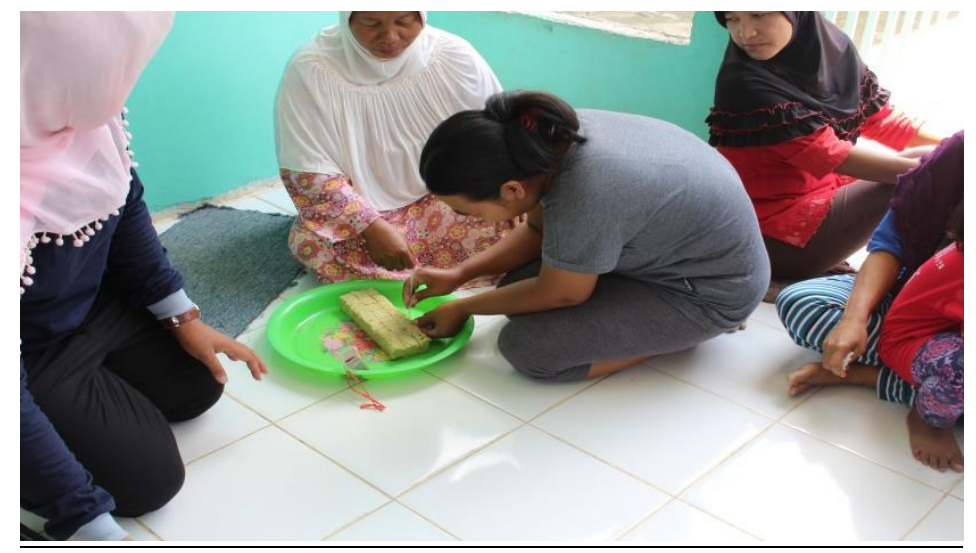

Gambar 2. Praktek Pembibitan Tanaman

Pada Gambar 2 diatas terlihari beberapa Ibu-ibu sedang belajar melakukan pembibitan dengan media tanam berupah busah dan biji tumbuhan. Umumnya selama 3 hari bibit akan mulai berkecambah, lalu dalam usia seminggu bibit siap ditanam di media pot di Hydroponik

3. Melakuan Pemindahan Bibit dan Pengenalan Waktu Panen 


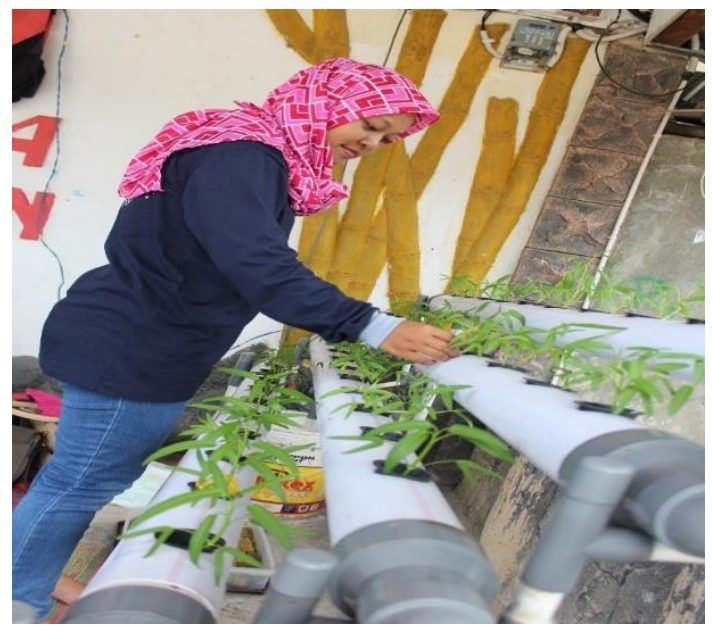

Gambar 3. Pemindahan Bibit Ke Media Tanam Hdyroponik

Setelah biji berkecambah dalam umur 3 hari, kecambah tersebut boleh dimasukakan kedalam pot tanam hydroponic. Berikut pada gambar 3 terlihat tanaman yang sudah berumur satu minggu (7 hari). Tentu tanaman harus dirawat secara berkala agar terhindar dari berbagai macam hama dan harus melihat intensitas air yang mengalir pada media tanam. Tanaman tersebut dalam usia 2 minggu sudah bisa dipanen tentu dengan kualitas yang organic, dikarenakan memang dalam proses penanaman tidak menggunakan pupuk kimia. Akhirnya melalui kegiatan ini masyarakat sei pelungkut telah mengetahui bahwa dengan lahan yang terbatas mereka juga dapat berkebun di halaman rumah mereka masing-masing. Program ini tentu dapat meringankan biaya belanjar kebutuhan sayur setiap bulannya.

\section{KESIMPULAN}

Berdasarkan uraian dari implementasi serta uraian pada bagian lainnya, maka dapat ditarik kesimpulan mengenai PPP selama 2 hari di RW 014 Kavling Flamboyan,Kecamatan Sagulung,Batam adalah sebagai berikut:

1. Pelaksanaan program dapat berjalan dengan baik hal ini tidak terlepas dari dukungan semua pihak terutama pemerintahan desa beserta lembaga desa serta masyarakat. 
2. Masyarakat sangat antusias dalam membantu pelaksanaan kegiatan yang diadakan terutama para ibu-ibu kavling flamboyan yang selalu ikut dalam rangkaian kegiatan.

3. Penamaman dengan cara hidroponik di RW 014 Kavling Flamboyan,Kecamatan Sagulung, Batam memiliki potensi yang cukup besar untuk dikembangkan di tempat lainnya sehingga dapat membuat dampak yang lebih besar pada masa yang akan datang, terutama bagi masyarakat yang tidak mampu bisa mendapatkan asupan sayurmayur secara berkala dan organik.

\section{REFERENSI}

Kemenristekdikti. 2016. Panduan Pelaksanaan Penelitian dan Pengabdian Masyarakat di Perguruan Tinggi. Edisi X.

Mulyana, Deddy. 2001. Ilmu Komunikasi Suatu Pengantar. Bandung: Rosda

Creswell, John W. 2010. Research Design. Pendekatan Kualitatif, Kuantitatif, dan Mixed. Yogyakarta: Pustaka Pelajar 